\title{
Impact of gum chewing on recovery of bowel activity after caesarean section
}

\author{
Manisha*, Nirmala Duhan
}

Department of Obstetrics and Gynecology, Pt. B.D. Sharma PGIMS, Rohtak, Haryana, India

Received: 30 December 2019

Revised: 23 January 2020

Accepted: 29 January 2020

\author{
*Correspondence: \\ Dr. Manisha, \\ E-mail: manishachaudhary996@gmail.com
}

Copyright: () the author(s), publisher and licensee Medip Academy. This is an open-access article distributed under the terms of the Creative Commons Attribution Non-Commercial License, which permits unrestricted non-commercial use, distribution, and reproduction in any medium, provided the original work is properly cited.

\section{ABSTRACT}

Background: Childbirth is a memorable part in every woman's life. Each labour experience is unique and calls for a celebration. Objective of this study was to evaluate the effect of gum chewing on recovery of bowel motility after caesarean section.

Methods: This prospective randomized controlled trial was conducted on 220 women who had undergone cesarean section and were further sub-divided into two groups of 110 women each Group I (Study group, n=110) in whom chewing gum was advised postoperatively and Group II (Control group, $n=110$ ) who were managed as per standard departmental postoperative feeding protocol.

Results: Mean age in Group A women was 24.86 \pm 3.89 years and 25.28 \pm 3.34 years in Group B. There was no statistically significant difference between the study and control group regarding their age, parity, occupation, LSCS/previous abdominal surgery, type of cesarean section, indications of cesarean section, skin incision, intraperitoneal adhesions. The mean time of bowel sound appearance in Group A was $3.27 \pm 0.95$ and it was $8.22 \pm 2.0$ hours in Group B. The mean time of passage of flatus was found to be 9.77 \pm 3.21 hours in Group A and 7.15 \pm 3.07 hours in Group B. In Group A, the mean time of passage of stools was $18.79 \pm 4.23$ hours and it was $39.12 \pm 6.56$ hours in Group B. Mean duration of hospital stay was significantly lesser (3.23 \pm 0.60 days) in gum chewing group than in the non-gum chewing group (4.18 \pm 1.28 days). Seventy-six $(69.09 \%)$ women of Group A needed only one chewing gum before appearance of bowel sound / flatus / feces. Only three women required three chewing gums. Out of 31 cases, who required two chewing gums, five were of previous 1 LSCS and 12 were previous 2 LSCS, thus suggesting delayed return of gut motility in women with $>1$ previous LSCS.

Conclusions: It was evident that gum chewing, a form of sham feeding is considered as an effective and inexpensive method which hastens the return of gut motility after caesarean section.

Keywords: Bowel activity, Caesarean section, Gum chewing

\section{INTRODUCTION}

Childbirth is a memorable part in every woman's life. Each labour experience is unique and calls for a celebration. ${ }^{1}$ Several techniques are used to perform child delivery in maternity care. Commonly, the delivery procedures are addressed as vaginal deliveries and caesarean sections. Caesarean section (CS), is a surgical procedure in which one or more incisions are made through a mother's abdomen and uterus to deliver one or more babies. ${ }^{2}$ International health community has considered ideal rate of caesarean section of $10-15 \%$. Average caesarean section rate in India is $12 \%$ in public institutions and it is much higher $(28 \%)$ in private sectors. ${ }^{3}$ Although it can be life saving for the mother and baby when necessary, it has the risk of producing more 
complications than normal vaginal birth. One of the postoperative complications could be related to the return of bowel motility after the surgery. ${ }^{4}$ Early return of gut motility leads to early starting of oral feeding, early breastfeeding, early ambulation and early discharge from the hospital and decreases overall cost of hospitalisation.

After the surgery, the return of the motility is typically first observed in the small bowel in less than 24 hours, then in the stomach between 24 and 48 hours, and finally in the large bowel after more than 48 hours. Nevertheless, the recovery of the large bowel function is much less predictable when compared to other parts of the gastrointestinal tract, thus clinicians use endpoints such as the passage of stool and flatus as indicators of clinical resolution of ileus. ${ }^{5}$

Postoperative ileus (POI) is a malfunction of intestinal motility after a major intra-or extra-abdominal surgery resulting from a non-mechanical insult that disrupts the normal coordinated propulsive motor activity of the gastrointestinal tract. The incidence of postoperative ileus is the greatest after a bowel surgery (20\%), but it can also occur after cholecystectomy $(8.5 \%)$, appendectomy $(6 \%)$, hysterectomy (4\%) and gynaecological surgery is 10$15 \%$. Overall incidence of ileus for all operative procedures in the abdomen is approximately $8.5 \% .^{6}$ Ileus is one of the most major problems of post-abdominal surgery along with increased hospital stay, pain, and abdominal distension, inability to start feeding, breastfeeding, and eventually delay in recovery during post postpartum period. ${ }^{7}$

Nasogastric suctioning, early feeding, intravenous fluid injection, local analgesia, reducing intravenous drug consumption, minimal surgical manipulation, use of cyclooxygenase inhibitors, non-steroidal antiinflammatory drugs, and drinks with high carbohydrate content have all been tried in efforts to reduce the occurrence of postoperative ileus. ${ }^{8}$

The postpartum period is a time of major physical and psychological transition for the new mother and the entire family. The primary goal of nursing care is to ensure the best possible preparation for the mother and the newborn. Sham feeding which is process of chewing food but spitting it out before swallowing has been reported to stimulate motility of the human duodenum, stomach, and the rectosigmoid.

Chewing gum has recently been used to stimulate the acceleration of gut function after abdominal, obstetrics and gynecologic surgeries, leading to stimulation of bowel motility. This response occurs after chewing to prepare the gut for food intake when actually normal food is eating, the intestine might not be able to handle it in the right away. Chewing gum use after caesarean section has been associated with various improved outcomes, including early passage of flatus, early bowel sounds and shorter lengths of hospitalization. In addition, there is no evidence of any side effects caused by gum chewing in literature. $^{9}$

The POI incidence and consequences in caesarean section cases was considerably reduced when chewing gum was used for 30 to 60 mins for minimum 3 times/day in a study of Craciunas et al. ${ }^{7}$ Gum-chewing immediately after surgery may be a cheap and harmless way to reduce postoperative ileus.

As per available literature, there is only one study on Indian population done by Deshpande et al on the possible impact of gum chewing on caesarean section patients' recovery of bowel function in India to the best of this knowledge. ${ }^{4}$ The present study was being planned to evaluate the effect of this form of sham feeding on recovery of bowel activity after caesarean section in this population.

\section{METHODS}

This randomized controlled trial was conducted in the department of obstetrics and gynecology at Pt. B.D. Sharma PGIMS, Rohtak. After obtaining written and informed consent, women who underwent elective/emergency caesarean section during routine hospital hours under spinal/general anesthesia were included in the study. Women with previous history of gastrointestinal surgery, diabetes mellitus, hypothyroidism, premature rupture of membranes, obstructed labour, prolonged labour, those underwent other extensive intraabdominal surgery as a result of intraoperative complications, water and electrolyte disturbances, history of drug consumption especially opioids and inability to chew gum were excluded from the study.

A total of 220 women who underwent caesarean section were enrolled in the study and were further sub-divided into two groups of 110 women each by a computer random number generator after the end of caesarean section. Group I (Study group) included 110 women in whom chewing gum was administered postoperatively while Group II (Control group) included another 110 women who were managed as per standard departmental postoperative feeding protocol.

\section{Caesarean section}

All caesarean sections were carried out by uniform technique of lower segment caesarean delivery during routine hospital hours. No enema/specific bowel preparation was done for caesarean section. Abdominal gauze pack to pack the bowel out of the operative field was not used during caesarean section. The uterovesical peritoneum and parietal peritoneum was left unsutured to reperitonize on its own. No oral or rectal bowel stimulant was administered to any patient in the study. Indication of caesarean section, number of hours in labor, cervical dilatation at the time of caesarean section, neonatal 
outcome and any maternal complications were noted. One transdermal skin patch containing $200 \mathrm{mg}$ of diclofenac and paracetamol infusion $1000 \mathrm{mg}$ intravenous 8 hourly in the first 24 hours was used for analgesia. Need for additional analgesic, any postoperative complications like nausea, vomiting, abdominal distension or any other was noted.

\section{Methodology}

A 3 grams liquid filled gum with artificial sweeteners $0.05-0.5 \%$ was used in the study. Gum chewing was initiated in patients of Group I within 2 hours of completion of surgery and the subjects were instructed to chew it for 15 minutes every 2 hours till the bowel sounds became auscultable or the first flatus was passed or 12 hours elapse whichever was earlier. The total number of gums chewed was noted. In Group II (control group) patients were encouraged to initiate feeding after 12 hours or once the bowel sounds become auscultable or the first flatus was passed whichever was earlier, with liquids and semisolids followed by regular solid diet.

\section{Evaluation of bowel activity}

Bowel sounds was checked with aural stethoscope every 2 hours after surgery till they were heard or 12 hours elapse whichever was earlier. Patient was asked to intimate about the feeling of passage of first flatus and also passage of first stools after surgery. In women who did not developed auscultable bowel sounds or passed flatus or stools by 12 hours after surgery, the bowel sounds was auscultated every 6 hours for the next 12 hours. This was accompanied by inquiry regarding first passage of flatus / stools. However, no gum chewing was offered to the women during these 12 hours. The time duration between end of surgery and first appearance of bowel sounds, first passage of flatus and faces were the primary outcome measures while abdominal distension, any adverse effects of chewing gum like nausea/vomiting and duration of hospital stay were the secondary outcome measures in the study. Postoperative paralytic ileus was defined as absent bowel sounds, non-passage of flatus or bowel movements and abdominal distension persisted longer than 24 hours or requiring nasogastric tube placement. Any other maternal complication, if it developed, was also noted.

\section{Statistical analysis}

The data so collected was analysed by Statistical package for social sciences (SPSS version 20). Chi-square test and Student t-test was used to statistically analyse the data. A probability value (p) of less than 0.05 was considered as statistically significant.

\section{RESULTS}

Majority of women belonged to 24-28 years age group i.e. fifty-two (47.27\%) in Group A and sixty (54.54\%) in
Group B with age range of 19-43 years and 19-35 years, respectively (mean age in Group A women was $24.86 \pm 3.89$ years and 25.28 \pm 3.34 years in Group B (p $0.393)$. The range of parity was $0-4$ in both the groups [mean parity in Group I was $(0.63 \pm 0.89)$ in Group I and in Group II it was $(0.87 \pm 0.96)$ ( $\mathrm{p} 0.06)]$. Seventy-nine $(71.81 \%)$ in Group A and $69(62.72 \%)$ in group B were primi gravida (p 0.07). Only thirty-one $(28.17 \%$ ) women in Group A and forty-one (37.2\%) in Group B were of previous caesarean section cases. Emergency caesarean section was carried out in a total of $101(91.81 \%)$ in Group A and $102(92.72 \%)$ in Group B. Elective caesarean was performed in $9(8.18 \%)$ and $8(7.27 \%)$ women in Group A and B, respectively $(\mathrm{p}=0.800)$.

Fetal distress was the most common caesarean section indication i.e. fifty-seven $(51.81 \%)$ and forty-four $(40 \%)$ women in Group A and B, respectively. Among the elective caesarean cases, previous LSCS was the most common indication i.e. twenty-six $(23.63 \%)$ and fortyone $(37.27 \%$ ) in Group A and B, respectively. In majority of women, spinal anaesthesia was used i.e., 107 (97.27\%) in Group A and $101(91.81 \%)$ in Group B, while the remaining were carried under general anaesthesia ( $p$ 0.074). Pfannensteil incision was needed in 107 (97.27\%) women in both the groups. Adhesions were found in 10 $(9.09 \%)$ women of Group A and $18(16.36 \%)$ women of Group B ( $\mathrm{p}=0.105)$.

Number of chewing gums chewed by the participants of Group A $(n=110)$ showed that seventy-six $(69.09 \%)$ women chewed only one chewing gum before appearance of bowel sound/flatus/feces. Only 3 women required 3 chewing gums. All these three were of previous 2 LSCS cases. Out of 31 cases, who required 2 chewing gums, 5 were of previous 1 LSCS and 12 were previous 2 LSCS.

Table 1: Time of bowel sound appearance (hours).

\begin{tabular}{|ll|l|}
\hline Time (hours) & $\begin{array}{l}\text { Group A }(\mathbf{n}= \\
\mathbf{1 1 0} \mathbf{n}(\boldsymbol{\%})\end{array}$ & $\begin{array}{l}\text { Group B }(\mathbf{n}= \\
\mathbf{1 1 0}) \mathbf{n}(\%)\end{array}$ \\
\hline$<2$ & $0(\%)$ & $0(\%)$ \\
\hline $2-4$ & $76(69.09 \%)$ & $0(\%)$ \\
\hline $4-6$ & $33(30 \%)$ & $15(13.63 \%)$ \\
\hline $6-8$ & $1(0.90 \%)$ & $6(5.45 \%)$ \\
\hline $8-10$ & 0 & $69(62.72 \%)$ \\
\hline $10-12$ & 0 & $17(15.45 \%)$ \\
\hline $12-14$ & 0 & $2(1.81 \%)$ \\
\hline $14-16$ & 0 & 0 \\
\hline $16-18$ & 0 & 0 \\
\hline $18-20$ & 0 & 0 \\
\hline $20-22$ & 0 & 0 \\
\hline $22-24$ & 0 & $1(0.90 \%)$ \\
\hline Range (hours) & $2-6.5$ & $6-24$ \\
\hline Mean \pm SD (hours) & $3.27 \pm 0.95$ & $8.22 \pm 2.0$ \\
\hline p $=0.000$ (<0.001 HS). & \\
\hline
\end{tabular}

Demonstrates mean time of bowel sound appearance in both the groups (Table 1). 
Table 2: Time of passage of flatus (hours).

\begin{tabular}{|lll|}
\hline $\begin{array}{l}\text { Time } \\
\text { (hours/min) }\end{array}$ & $\begin{array}{l}\text { Group A }(\mathbf{n}= \\
\mathbf{1 1 0}) \mathbf{n}(\boldsymbol{\%})\end{array}$ & $\begin{array}{l}\text { Group B }(\mathbf{n}= \\
\mathbf{1 1 0}) \mathbf{n}(\%)\end{array}$ \\
\hline $1-5$ & $4(3.63 \%)$ & $0(\%)$ \\
\hline $6-10$ & $82(74.54 \%)$ & $0(\%)$ \\
\hline $11-15$ & $19(17.27 \%)$ & $17(15.45 \%)$ \\
\hline $16-20$ & $3(2.72 \%)$ & $88(80 \%)$ \\
\hline $21-25$ & $1(0.90 \%)$ & $3(2.72 \%)$ \\
\hline $26-30$ & $1(0.90 \%)$ & $1(0.90 \%)$ \\
\hline $31-35$ & 0 & 0 \\
\hline$>35$ & 0 & $1(0.90 \%)$ \\
\hline Range & $4.3-28$ & $14-36$ \\
\hline Mean \pm SD & $9.77 \pm 3.21$ & $17.15 \pm 3.07$ \\
\hline p $=0.000(<0.001 \mathrm{HS})$. & \\
\hline
\end{tabular}

Time of passage of flatus in both the groups of the present study (Table 2).

Table 3: Time of passage of stools (hours) after surgery.

\begin{tabular}{|lll|}
\hline Time (hours) & $\begin{array}{l}\text { Group A }(\mathbf{n}= \\
\mathbf{1 1 0}) \mathbf{n}(\%)\end{array}$ & $\begin{array}{l}\text { Group B }(\mathbf{n}= \\
\mathbf{1 1 0}) \mathbf{n}(\%)\end{array}$ \\
\hline $0-15$ & $4(3.63 \%)$ & 0 \\
\hline $16-20$ & $89(80.90 \%)$ & 0 \\
\hline $21-25$ & $11(10 \%)$ & 0 \\
\hline $26-30$ & $4(3.63 \%)$ & $10(9.09 \%)$ \\
\hline $31-35$ & 0 & $13(11.81 \%)$ \\
\hline $36-40$ & $1(0.90 \%)$ & $54(49.09 \%)$ \\
\hline $41-45$ & 0 & $10(9.09 \%)$ \\
\hline $46-50$ & $1(0.90 \%)$ & $21(19.09 \%)$ \\
\hline $51-55$ & 0 & $1(0.90 \%)$ \\
\hline $56-60$ & 0 & 0 \\
\hline $61-65$ & 0 & 0 \\
\hline $66-70$ & 0 & 0 \\
\hline$>70$ & 0 & $1(0.90 \%)$ \\
\hline Range & $14-48$ & $28-72$ \\
\hline Mean \pm SD & $18.79 \pm 4.23$ & $39.12 \pm 6.56$ \\
\hline
\end{tabular}

$\mathrm{p}=0.000(<0.001 \mathrm{HS})$.

Time of passage of stools in both the groups of the study. (Table 3).

In this study one transdermal skin patch containing 200 $\mathrm{mg}$ of diclofenac and $1000 \mathrm{mg}$ paracetamol infusion intravenously 8 hourly for first 24 hours was used for analgesia and there is no need for additional analgesics in any patient in this study. In the present study, nausea/vomiting was found in only one patient of Group A and three patients of Group B with statistically insignificant difference ( $p$ 0.312). Abdominal distension was found in only one patient of Group A and eleven patients of Group B with statistically highly significant difference ( $\mathrm{p}$ 0.000). Mean duration of hospital stays of $3.23 \pm 0.60$ days found in Group $\mathrm{A}$ as compared to $4.18 \pm 1.28$ days in Group B. Hospital stay was significantly lesser in Group A than Group B.

\section{DISCUSSION}

The current study aimed to evaluate the impact of gum chewing on recovery of bowel activity after caesarean section.

The study findings revealed that there was no statistically significant difference between both groups as compared to their general characteristics, age groups, parity, occupation, LSCS/previous abdominal surgery, type of caesarean section, indication of caesarean section, type of anaesthesia, skin incision. These findings were comparable to the other studies reported in the literature.

The physiological mechanisms for enhanced recovery of bowel motility by gum chewing is achieved to be activation of cephalic vagal pathways, which is stimulating intestinal myoelectric activity in an attempt to counteract, activation of gastrointestinal, $\mu$ opioid receptors. This response leads to both humoral and nervous stimulation of bowel activity.

Sham feeding which is process of chewing food, but spitting it out before swallowing has been reported to stimulate motility of human duodenum, stomach and rectosigmoid. The researchers demonstrated that sham feeding increased the serum concentration of peptide hormone gastrin, the neuropeptide, neurotensin, pancreatic polypeptide. Besides, sham feeding also increases duodenal alkaline secretions. Gum chewing mimics food intake is considered as a kind of sham feeding. ${ }^{10}$

Ledari et al study on effect of postoperative gum chewing on recovery of bowel function after caesarean section on 100 women. ${ }^{11}$ These women were well tolerating the gum and no feeling of dissatisfaction and none were therefore excluded from the study. The study findings has shown reduce time of appearance of first bowel sounds, first passage of flatus and first passage of stool and reduced duration of hospital stay following gum chewing after caesarean section.

\section{Time of bowel sound appearance}

Time of bowel sound appearance depends on effect of anaesthesia, gut handling, duration of surgery, also depends on intraperitoneal adhesions in surgery, blood loss during surgery, also history of previous abdominal surgery or caesarean section. ${ }^{10}$

The mean time of first appearance of bowel sounds in this study was (3.27 \pm 0.95 hours) in study group as compared to control group $(8.22 \pm 2.0$ hours) and the difference was statistically significant $(\mathrm{p}=0.000)$.

These findings were in accordance with study by Rashad et al, on effect of gum chewing after caesarean section on gastrointestinal function recovery. ${ }^{12}$ 


\section{Time of first passage of flatus}

After surgery, the return of motility is typically first observed in small bowel in less than 24 hours than in the stomach between 24 and 48 hours and finally in the large bowel after more than 48 hours (most often after three days). ${ }^{10}$ Return of motility depends on many factors like blood loss (if blood loss is more decreased motility), bowel manipulation during surgery, anesthetic agents like halothane slows gastric motility whereas nitrous oxide has pro motility properties. Also depends on type of surgery like orthopedic and extremities surgery and abdominal surgery (special colorectal surgery) delays bowel motility by causing sympathetic stimulation and also manipulation of intestine in abdominal surgery as compared to caesarean section. ${ }^{1}$

Return of gut motility after caesarean section depends only factors like emptiness of stomach, adhesions during surgery and blood loss during surgery, duration of surgery and type of anesthesia (spinal or general). Motility will be delayed if full stomach, intraperitoneal adhesions and lengthy surgery or under general anaesthesia. $^{13-16}$

Time of first passage of flatus in study group varies

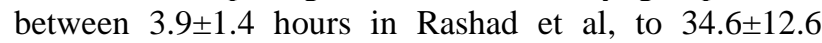
hours in Shang et al. ${ }^{12,17}$ In control group, it varies between $7.65 \pm 2.42$ hours. In study by Mansour et al to $39.9 \pm 13.5$ hours in Shang et al, study. ${ }^{9}$

In this study time of first passage of flatus in study group i.e. $9.77 \pm 3.21$ hours while $17.15 \pm 3.07$ hours in control group and this time was comparable with other studies.

\section{Time of first passage of stools}

Gum chewing results in early passage of stools after surgery because it is a type of sham feeding that stimulates motility of human stomach, duodenum and rectosigmoid. It increases serum concentration of peptide hormone gastrin, neuropeptide neurotensin, pancreatic polypeptide. So, it leads to early passage of flatus, early bowel sounds, and shorter length of hospital stay. ${ }^{10}$

Time of first passage of stools after surgery in study group varies between $10.25 \pm 2.15$ hours in the study by Mansour et al to $67.4 \pm 19.4$ hours in Shang et al, study while in control group it varies between $11.58 \pm 1.96$ hours to $74.50 \pm 25.31$ hours in various studies. ${ }^{9,17}$ In this study the time of first passage of stool after surgery in study group is $18.79 \pm 4.23$ hours and $39.12 \pm 6.56$ hours in control group which is comparable to studies reported in literature.

\section{Abdominal complications}

In studies reported in literature, none of the patients had any side effects of chewing gum. In this study, only two $(1.8 \%)$ patients in study group had abdominal complications (nausea, vomiting and abdominal distension) as compared to fourteen $(12.72 \%)$ patients in control group.

\section{Hospital stay (days)}

Gum chewing also decreases duration of hospital stay by causing early passage of flatus and stools after surgery by decreasing incidence of postoperative ileus and decreasing the cost of treatment and associated complications like infection, bed sores and venous thromboembolism etc. ${ }^{4}$

In this study, the mean duration of hospital stay was in study group is $3.25 \pm 0.60$ days while in control group it is $4.18 \pm 1.28$ days with statistically significant difference (p $<0.001$ ). The results were comparable to study done by Jakkaew et al, in which mean duration of hospital stay was $3.03 \pm 0.03$ days in study group versus $3.24 \pm 0.71$ days in control group. ${ }^{18}$

In this study the mean duration of hospital stay was less because during surgery use of current department protocol, pfannesteil skin incision, patients with no maternal/neonatal complications, use of absorbable sutures, early bowel sounds, early passage of flatus and early passage of stools after surgery. Early ambulation, less duration of hospital stay leads to early return to work or day to day activities, decreases the overall cost on healthcare system. ${ }^{4}$

\section{CONCLUSION}

It can thus be concluded from the present study that sham feeding hastens the return of gut motility after caesarean section as is evident by significantly lesser time required for bowel sound appearance, passage of flatus and stools. This is also true for previous caesarean section cases in whom the return of gut motility is delayed. Also, sham feeding is associated with less nausea/vomiting, abdominal distension and a shorter hospital stay. Hence, gum chewing can be recommended as a routine postoperative measure to hasten gut movement in women who have undergone caesarean section. However, this study included only 220 cases of caesarean section even though the incidence of caesarean deliveries has increased tremendously in the last decade, thus larger studies evaluating sham feeding in caesarean section population are advocated.

Funding: No funding sources Conflict of interest: None declared

Ethical approval: The study was approved by the Institutional Ethics Committee

\section{REFERENCES}

1. Matros E, Rocha F, Zinner M, Wang J, Ashley S, Breen E, et al. Does gum chewing ameliorate postoperative ileus? Results of a prospective, 
randomized, placebo-controlled trial. J Am Coll Surg. 2006;202:773-8.

2. Pereira S, Portela F, Santos M, Machado J, Abelha A. Predicting type of delivery by identification of obstetric risk factors through data mining. Procedia Computer Science. 2015;64:601-9.

3. World health organization. WHO statement on caesarean section rates. Executive Summary, WHO 2015. Available at: https://www.healthynewbornnetwork.org/resource/w ho-statement-on-caesarean-section-rates-executivesummary/. Accessed on 26 December 2019.

4. Deshpande H, Madkar C, Kale N, Sable U, Bobe A. The study of effect of sugar free chewing gum on peristalsis activity in post-caesarean patients. Indian J Res. 2017;6:4-7.

5. Fraser D, Copper M. Myles text book for midwives. $14^{\text {th }}$ ed. London: Churchill Livingstone; 2004:455481 .

6. AboBaker RM. Effect of chewing gum on bowel motility in women undergoing post-operative caesarean section. Int $\mathrm{J}$ Innov Res Med Sci. 2018;3:25-8

7. Craciunas L, Sajid S, Ahmed A. Chewing gum in preventing postoperative ileus in women undergoing caesarean section: a systematic review and metaanalysis of randomized controlled trials. Br J Obstet Gynecol. 2014;121:793-9.

8. Hirayama I, Suzuki M, Ide M, Asao T, Kuwano H. Gum-chewing stimulates bowel motility after surgery for colorectal cancer. Hepato Gastroenterol. 2006;53:206-8.

9. Mansour S, Elnegeri M, Ibrahim A. Chewing gum after caesarean section: it's effect on regaining intestinal function. IOSR J Nurs Hlth Sci. 2016;5:758.

10. Safdari DF, Salehian T, Parvin N, Akbari N. Comparison of the effects of gum chewing with those of early initiation of oral feeding and routine regimen on recovery of bowel function in primiparous women after caesarean section. Sci J Kurdistan Univ Med Sci 2011;16:9-15.
11. Ledari FM, Barat S, Delavar MA. Chewing gum has stimulatory effects on bowel function in patients undergoing caesarean section: a randomized controlled trial. Bosnian J Basic Med Sci. 2012;12:265-8.

12. Rashad W, Alyousef S. Effect of sugarless gum chewing on intestinal movement after caesarean section. Life Sci J. 2013;10:3257-61.

13. Saxena A, Mahendru V. Factors affecting bowel motility following abdominal surgery: a clinical study. Saudi Surg J. 2015;3:1-6.

14. Andersen HK, Lewis SJ, Thomas S. Early enteral nutrition within 24 hours of colorectal surgery versus later commencement of feeding for postoperative complications. The Cochrane Database Syst Rev. 2006;18(4):CD004080.

15. Watt DG, McSorley ST, Horgan PG, DC MM. Enhanced recovery after surgery: which components, if any, impact on the systematic inflammatory response following colorectal surgery: a systematic review. Med. 2015;94(36):e1286.

16. Ho YM, Smith SR, Pockney P, Lim P, Attria J. A meta-analysis on the effect of sham feeding following colectomy: should gum chewing be included in enhanced recovery after surgery protocols. Dis Colon Rect. 2014;57:115-26.

17. Shang H, Yang Y, Tong X, Zhang L, Fang A, Hang L. Gum chewing slightly enhances early recovery from postoperative ileus after caesarean section: results of a prospective, randomized, controlled Trial. Am J Perinatol. 2010;2:387-91.

18. Jakkaew B, Charoenkwan K. Effects of gum chewing on recovery of bowel function following caesarean section: a randomized controlled trial. Arch Gynecol Obstet. 2013;288:255-60.

Cite this article as: Manisha, Duhan N. Impact of gum chewing on recovery of bowel activity after caesarean section. Int J Reprod Contracept Obstet Gynecol 2020;9:1132-7. 